PREPARED FOR THE U.S. DEPARTMENT OF ENERGY, UNDER CONTRACT DE-AC02-76CH03073

PPPL-3635

PPPL-3635

UC-70

The Role of Axisymmetric Reconnection Events in JET Discharges with Extreme Shear Reversal

by

B.C. Stratton, J.A. Breslau, R.V. Budny, N.C. Hawkes, S.C. Jardin, W. Park, H.R. Strauss, and L.E. Zakharov

December 2001

NM|

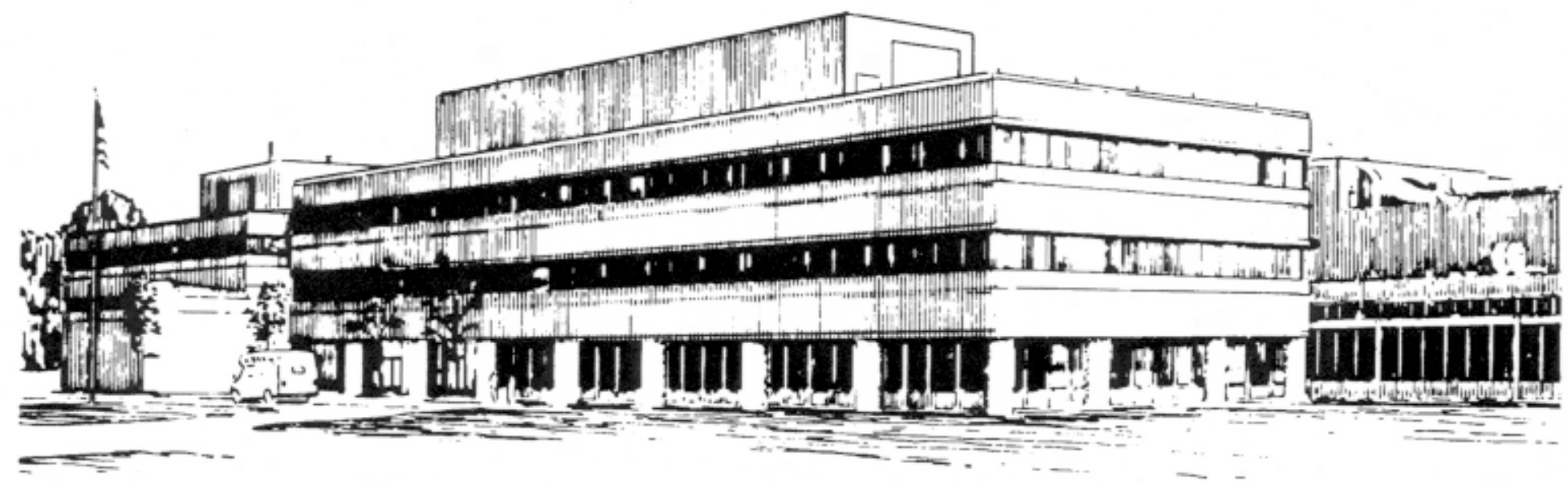

PRINCETON PLASMA PHYSICS LABORATORY PRINCETON UNIVERSITY, PRINCETON, NEW JERSEY 


\section{PPPL Reports Disclaimer}

This report was prepared as an account of work sponsored by an agency of the United States Government. Neither the United States Government nor any agency thereof, nor any of their employees, makes any warranty, express or implied, or assumes any legal liability or responsibility for the accuracy, completeness, or usefulness of any information, apparatus, product, or process disclosed, or represents that its use would not infringe privately owned rights. Reference herein to any specific commercial product, process, or service by trade name, trademark, manufacturer, or otherwise, does not necessarily constitute or imply its endorsement, recommendation, or favoring by the United States Government or any agency thereof. The views and opinions of authors expressed herein do not necessarily state or reflect those of the United States Government or any agency thereof.

\section{Availability}

This report is posted on the U.S. Department of Energy's Princeton Plasma Physics Laboratory Publications and Reports web site in Fiscal Year 2002. The home page for PPPL Reports and Publications is: http://www.pppl.gov/pub_report/

DOE and DOE Contractors can obtain copies of this report from:

U.S. Department of Energy

Office of Scientific and Technical Information

DOE Technical Information Services (DTIS)

P.O. Box 62

Oak Ridge, TN 37831

Telephone: (865) 576-8401

Fax: (865) 576-5728

Email: reports@adonis.osti.gov

This report is available to the general public from:

National Technical Information Service

U.S. Department of Commerce

5285 Port Royal Road

Springfield, VA 22161

Telephone: 1-800-553-6847 or

(703) 605-6000

Fax: (703) 321-8547

Internet: http://www.ntis.gov/ordering.htm 


\title{
The Role of Axisymmetric Reconnection Events in JET Discharges with Extreme Shear Reversal
}

\author{
B. C. Stratton ${ }^{1}$, J. A. Breslau' , R. V. Budny ${ }^{1}$, S. C. Jardin ${ }^{1}$, W. Park ${ }^{1}$, H. R. Strauss ${ }^{2}$, \\ L. E. Zakharov ${ }^{1}$, B. Alper ${ }^{3}$, V. Drozdov ${ }^{3}$, N. C. Hawkes ${ }^{3}$, S. Reyes-Cortes ${ }^{4}$ \\ and Contributors to the EFDA-JET Work Programme* \\ ${ }^{1}$ Princeton Plasma Physics Laboratory, PO Box 451, Princeton, NJ, 08543, USA \\ ${ }^{2}$ Courant Institute of Mathematical Sciences, New York University, 251 Mercer St, \\ New York, NY 10012, USA \\ ${ }^{3}$ Euratom/UKAEA Fusion Association, Culham Science Centre, Abingdon, Oxfordshire, \\ OX14 3DB, UK \\ ${ }^{4}$ Euratom/IST Association, Centro de Fusao Nuclear 1049-001, Lisboa, Portugal
}

\begin{abstract}
Injection of Lower Hybrid Heating and Current Drive into the current ramp-up phase of JET discharges can produce extremely reversed q-profiles characterized by a core region of very small or zero current density (within Motional Stark Effect diagnostic measurement errors) and $q_{\min }>1$. $T_{e}$-profiles show sawtooth-like collapses and the presence of an internal transport barrier. Accurate equilibrium reconstructions of these discharges are obtained using the ESC code, which was recently extended to allow equilibrium reconstructions in which a free boundary solver determines the plasma boundary and a fixed boundary solver provides the magnetic geometry and current density profile. The core current density does not appear to go negative, although current diffusion calculations indicate that sufficient non-inductive current drive to cause this is present. This is explained by nonlinear resistive MHD simulations in toroidal geometry which predict that these discharges undergo $n=0$ reconnection events (axisymmetric sawteeth) that redistribute the current to hold the core current density near zero.
\end{abstract}

*See annex to J. Pamela et al, Fusion Energy 2000 (Proc. 18 ${ }^{\text {th }}$ IAEA Conf., Sorrento, 2000) IAEA, Vienna. 


\section{Introduction}

Tokamak plasmas in which local heat and particle transport are reduced by the presence of an Internal Transport Barrier (ITB) [1,2] have been extensively studied in recent years because they can yield high performance at relatively low plasma current for a given value of the toroidal magnetic field, a desirable feature for a reactor. A straightforward way to induce an ITB is to form a region of low or negative magnetic field shear in the core of the discharge, often in combination with significant toroidal plasma flow. (The magnetic field shear is defined as $s \equiv(r / q)(d q / d r)$, where the safety factor, $q$, is the rate of change of toroidal flux, $\Phi$, with poloidal flux, $\psi, \partial \Phi / \partial \psi$.

Low or negative shear is experimentally produced by injection of neutral beam or radio frequency heating into the current ramp-up phase of the discharge. The heating decreases the plasma resistivity, which delays the penetration of the current to the core, resulting in a hollow profile of the current density, $j(R)$. (Unless otherwise stated, we use a cylindrical coordinate system $(R, \phi, Z)$ with the assumption of axisymmetry and the notation that $j(R)=j(R, \phi, Z=0)$ is the toroidal current density on the plasma midplane.) This effect can be enhanced by application of radio frequency current drive during the current ramp-up to produce a non-inductive component of the current density profile that is peaked off-axis. This has been done on the JET tokamak using Lower Hybrid heating and Current Drive (LHCD) and is referred to as the LHCD prelude [3].

Recently, discharges with extremely reversed shear have been produced on JET [4, 5]. In this regime, $j(R)$ in a small region near the magnetic axis, $\left|R-R_{A}\right| \leq 0.2 m$, is very small or zero within Motional Stark Effect diagnostic $[6,7]$ measurement errors. $\left(R_{A}\right.$ is the major radius of the magnetic axis.) This was inferred from the observation of a nearly flat region of zero magnetic field pitch angle, $\gamma=\tan ^{-1}\left(B_{Z} / B_{\phi}\right)$, where $B_{Z}$ is the vertical component of the magnetic field and $B_{\phi}$ is the toroidal component of the field. A similar phenomenon was recently observed in JT-60U, where the off-axis current drive was attributed to the bootstrap current generated by neutral beam injection [8]. JET discharges in this regime can exhibit transient high-performance during injection of high power neutral beam and ion cyclotron resonance heating following the LHCD prelude [9].

Following the initial observation of the nearly flat region of zero $\gamma, j(R)$ was derived directly from the magnetic field pitch angle profile measured by the MSE diagnostic using Ampére's Law [4]. This approach was taken because standard equilibrium reconstructions constrained by the measured pitch angle profiles were numerically unstable due to the fact that the scalar flux surface quantities appearing in the Grad- 
Shafranov equation are not well defined when the poloidal component of the magnetic field is small or zero. Subsequently, an improved measurement of $j\left(R_{A}\right)$ was obtained from a shot in which the plasma was rapidly moved in the radial direction so that a given point in the plasma was swept across adjacent spatial channels of the MSE diagnostic [5]. The slope of the variation in the measured pitch angle from a channel viewing the core region yielded $j\left(R_{A}\right)=0.08 \pm 0.025 \mathrm{MA} / \mathrm{m}^{2}$. (For comparison, the off-axis peak in $j(R)$ is $\sim 1 \mathrm{MA} / \mathrm{m}^{2}$.) Thus, the core current is very small. Approximate magnetic equilibrium reconstructions showed that the resulting q-profiles have large values in the plasma core and an off-axis minimum of $q_{\min }=1-3$ [5]. The gradient in $j(R)$ at the edge of the core region is very large.

Off-axis, non-inductive current drive in the same direction as the Ohmic current (cocurrent drive) causes the core current density to decrease because it induces a back electromotive force inside the non-inductive current peak that drives a negative current in the plasma core [4]. If the non-inductive current drive is strong enough relative to the Ohmic current, the total current can in principal be zero or negative in the core. This is a transient effect, but it can persist for several seconds in large, hot tokamaks such as JET and JT-60U because the total flux can not be changed rapidly. Analysis of a number of JET discharges in this regime showed that $j\left(R_{A}\right)=0$ within the $\gamma$ error bars in many cases but that it does not go negative [5], even though sufficient drive for this appeared to be present. Thus, there is a physical effect that clamps the core current at zero. In this paper, we demonstrate that these discharges undergo $n=0$ reconnection events (axisymmetric sawteeth) that rapidly redistribute the core current to keep it near zero.

We first demonstrate that reliable equilibrium reconstructions in discharges with zero core current density can be obtained using the perturbative technique for solving the Grad-Shafranov equation employed by the ESC code [10]. Negative core current density is predicted by a simple cylindrical model of the $\psi(r)$ time evolution that uses initial Ohmic and LHCD $j(R)$ profiles predicted by the TSC/LSC code [11]. This result demonstrates that additional physics is needed to explain the clamping of the core current density near zero. Resistive MHD simulations in toroidal geometry by the M3D code [12] predict the existence of reconnection events that redistribute the core current to hold it near zero.

\section{Experimental Scenario}

We focus on a JET discharge that is well diagnosed during the LHCD prelude (\#53488). This discharge had $B_{\phi}=2.5 \mathrm{~T}$, major radius $\mathrm{R}_{0}=2.96 \mathrm{~m}$, and minor radius 
$a=0.95 \mathrm{~m}$. The time evolution of the plasma current $\left(I_{p}\right)$, LHCD power, neutral beam power, and electron temperature $\left(T_{e}\right)$ from electron cyclotron emission measurements at $\mathrm{R}=3.0 \mathrm{~m}$ and $3.3 \mathrm{~m}$ are shown in figure 1. (Note that the plasma breakdown occurs at $0.5 \mathrm{~s}$ on the time scale used here.) 2.7 MW of LHCD power was injected for $2.6 \mathrm{~s}$ starting at $1.0 \mathrm{~s}$ into the discharge, with the launcher phased to drive current in the codirection. During this time, $\mathrm{I}_{\mathrm{p}}$ ramped from $0.9 \mathrm{MA}$ to $1.9 \mathrm{MA}$. The $\mathrm{T}_{\mathrm{e}}$ time evolution shows sawtooth-like crashes that are always seen during the LHCD prelude in discharges with extreme shear reversal. These 'high-q' sawteeth are similar to off-axis sawteeth observed in reversed shear plasmas on TFTR [13].

Neutral beam injection at 2-3 MW power started at $2.5 \mathrm{~s}$ into the discharge and lasted for $0.6 \mathrm{~s}$. The purpose of this short beam pulse was to allow MSE pitch angle and charge exchange spectroscopy ion temperature $\left(T_{i}\right)$ measurements during the LHCD prelude. Beam injection is not normally done before the end of the LHCD prelude due to beam shine-through resulting from the low plasma density of $n_{\mathrm{e}} \approx 1 \times 10^{19} \mathrm{~m}^{-3}$. Even this relatively low beam power level caused some perturbation to the plasma by the end of the beam pulse, so the pitch angles measured $0.1 \mathrm{~s}$ into the beam pulse are used in this study to ensure that the effect of the perturbation is negligible. The $T_{e}, T_{i}$ and $n_{e}$ profiles at $2.6 \mathrm{~s}$ into the discharge are shown in figure 2; these profiles are used as input to the modeling described later. Note the presence of a steep gradient on the $T_{e}$ profile, indicating the existence of an electron ITB at this early time. This is generally seen during the LHCD prelude in discharges with high-q sawteeth and low core current density.

The JET MSE polarimeter $[6,7]$ observes the Stark spectrum of the $D_{\alpha}$ emission from deuterium atoms injected into the plasma by the heating neutral beams. The Stark splitting is due to the Lorentz electric field seen by the beam atoms as a result of their motion across the magnetic field of the tokamak. The polarimeter measures the polarization angle, $\gamma_{\mathrm{m}}$, of the $\pi$ lines of the Stark spectrum, which are polarized parallel to the local electric field, or perpendicular to the magnetic field. The diagnostic is calibrated using measurements obtained during beam injection into the torus filled with gas only (no plasma) for which the field is accurately known. The overall uncertainty in the $\gamma_{m}$ measurement is typically $0.2-0.3^{\circ}$ when both the signal statistics and calibration uncertainties are taken into account.

For the discharge studied here, only one of the neutral beams seen by the diagnostic is injected at the time of interest. In this case, the components of the magnetic field are related to $\gamma_{m}$ by the expression 


$$
\tan \gamma_{m}=\frac{B_{Z} a_{0}+B_{R} a_{1}+B_{\phi} a_{2}}{B_{Z} a_{3}+B_{R} a_{4}+B_{\phi} a_{5}}
$$

where the coefficients $a_{n}$ describe the geometry of the diagnostic lines of sight and the neutral beam trajectories [6]. This relationship is complex but it can be simplified to allow the existence of a region of small or zero $j(R)$ to be inferred directly from the measured $\gamma_{m}$-profile. The dominant terms are those involving $a_{0}, a_{2}$, and $a_{5}$ [5]. Thus, for regions of small or zero $B_{Z}$, the difference between $\gamma$ and $\gamma_{m}$ is $\tan ^{-1}\left(a_{2} / a_{5}\right)$. This offset is approximately $-1.7^{\circ}$. It is due to the non-zero angle between the neutral beam trajectory and the plasma midplane and is accurately measured by beam injection into gas (no plasma) with the same value of the toroidal field as is used in the plasma measurements.

Figure 3 shows the $\gamma_{m}$-profile at $2.6 \mathrm{~s}$ into the discharge with the offset subtracted. The existence of a region around the plasma axis of nearly zero slope and $\gamma \approx 0^{\circ}$ is clearly seen. From the definition of $\gamma$, this implies $B_{z} \approx 0$, or $j(R) \approx 0$, in this region within measurement errors. The $\gamma$-profile at $1.75 \mathrm{~s}$ into the discharge measured in a similar shot shows a similar $\gamma \approx 0^{\circ}$ region, indicating nearly zero core current density at this time as well. Our present data set does not include measurements at earlier times, so it is not known how early this region develops. We plan to study this in future experiments.

It is well known that the radial component of the plasma electric field, $E_{r}$, can contribute to $\gamma_{m}$ [14]. A direct measurement of $E_{r}$ is not available on JET so the magnitude of this effect was estimated from the radial force balance equation using charge exchange spectroscopy measurements of the carbon ion $\mathrm{T}_{\mathrm{i}}$, density, and toroidal flow speed. A neoclassical estimate of the poloidal flow was used. The toroidal flow term is found to be the dominant contribution to $E_{r}$, but the overall effect on $\gamma_{m}$ is negligible compared to the measurement uncertainties because the toroidal flow speed is small due to the low beam power during the LHCD prelude $[4,5]$. Thus, this effect is ignored in this study.

\section{Equilibrium Reconstruction}

The ESC equilibrium reconstruction code [10] uses a perturbative approach to solve the nonlinear Grad-Shafranov equation in flux coordinates; the difference between the nonlinear equation and its linear form becomes a driving term in the next iteration of the solution. An explicit algorithm is used to advance the relationship between the flux coordinates and spatial coordinates. This approach allows the use of an efficient Newton 
scheme to solve the Grad-Shafranov equation. (A detailed description is given in reference 10.)

Recently, ESC has been extended to allow equilibrium reconstructions in which a free boundary solver determines the plasma boundary and a fixed boundary solver provides the magnetic geometry and current density profile. While the earlier ESC fixed boundary solver allows considerable flexibility in prescribing the plasma equilibrium input profiles (including the MSE $\gamma_{m}$-profiles), a new free boundary capability has been incorporated to solve for the plasma boundary and the input profiles consistent with the external magnetic probe and pickup loop measurements and the coil currents. For the present study, the JET plasma and divertor geometry, the coil currents, the signals from the magnetic probes and pickup loops located on the vacuum vessel walls, and the MSE $\gamma_{\mathrm{m}}$-profiles as described by equation 1 are used to constrain the reconstructions. The model of the JET iron core described in reference 15 is used. As mentioned above, $\psi$ is poorly determined for very hollow current density profiles. Thus, the flux surfaces are labeled by the variable $\mathrm{x}=\left(\Phi / \Phi_{0}\right)^{1 / 2}$ where $\Phi_{0}$ is the total toroidal flux through the plasma cross-section. (Note that $x \approx r / a$ in the midplane.)

Figure 4 shows the equilibrium configuration obtained by ESC for the plasma described in the previous section and shown in figures 1-3. The corresponding profiles of the parallel current density, $\mathrm{j}_{\|}(\mathrm{x})$, and the $\mathrm{q}$-profile, $\mathrm{q}(\mathrm{x})$, are shown in figures 5 and 6 , respectively. Figure 7 shows the fit to $\tan \gamma_{m}(R)$ from the MSE measurements; the fit reproduces the nearly flat core region and the transition to the exterior region of the $\tan \gamma_{\mathrm{m}}$-profile. The fit to the magnetic probe and pickup loop signals (not shown) is very good.

The $\mathrm{j}_{\|}(\mathrm{x})$ profile shown in figure 5 has several interesting features. There is a region of nearly zero current density around the plasma axis with a steep positive gradient at its edge. It is not possible to accurately determine $j_{\|}(x)$ in this core region because it is very sensitive to the choice of fit to $\tan \gamma_{m}$ within the measurement uncertainties; thus, the reconstructions can not distinguish between zero current in this region and small finite current. The MSE $\gamma_{m}$-profile near the plasma axis suggests a negative current density over a small region in the core with possibly zero total current within a slightly larger region. At present, ESC can not reproduce such an equilibrium and the slightly negative off-axis value of $\mathrm{j}_{\|}(\mathrm{x})$ is indicative of the reduction in the total current needed to compensate for the small positive $\mathrm{j}_{\|}(\mathrm{x})$ on axis.

There is a narrow spike in $\mathrm{j}_{\|}(\mathrm{x})$ peaking at $\mathrm{x}=0.25$ at the edge of this core region and a corresponding spike in the q-profile at this radius, as shown in figure 6 . This feature and the steep gradient inside it arise from the sharp change in slope of the tan $\gamma_{\mathrm{m}}$-profile 
at the edge of the nearly flat region shown in figure 5 . It is not possible to simultaneously perfectly fit this discontinuity in the tan $\gamma_{m}$-profile on both sides of the magnetic axis (indicated by the vertical line in figure 5). This inconsistency between the portions of the $\tan \gamma_{m}$-profile on either side of the magnetic axis is probably due to limitations of the MSE diagnostic calibration. However, ESC runs in which fitting to the inner and outer parts of the $\tan \gamma_{\mathrm{m}}$-profile were emphasized shows that the spike in $\mathrm{j}_{\|}(\mathrm{x})$ at the edge of the core region is always obtained, and we therefore believe that it is a real feature of the $j_{\|}(x)$ profile. The $\mathrm{j}_{\|}(\mathrm{x})$ spike may be the response of the plasma to current redistribution caused by the magnetic reconnection events in the core discussed in the following section. The second $j_{\|}(x)$ peak at $x=0.57$ is broader and is due to the off-axis LHCD current density, although the position of this peak is uncertain because it occurs at sufficiently large radius that the reconstructed $\mathrm{j}_{\|}(x)$ is determined by the external magnetic probe and pickup loop measurements as well as the MSE $\gamma_{m}$-profile. The smaller peaks in the $j_{\|}(x)$ profile of figure 5 arise from the details of the fitting to the tan $\gamma_{m}$ profile and therefore may not be physical.

\section{Estimate of Negative Core Current Drive}

As discussed in the introduction, off-axis LHCD in the co-direction will transiently reduce the current density inside the off-axis peak and can in principal drive it negative. The magnitude of this effect must be estimated to serve as an initial condition for the MHD stability calculations to follow. This can not be done using tokamak transport/equilibrium codes such as TSC/LSC [11] or TRANSP [16] because the equilibrium solvers fail when the current density reverses. Instead, a simple code was used to solve the following equation for the time evolution of $\psi(r)$ in cylindrical geometry:

$$
\frac{\partial \psi}{\partial t}=\eta_{\|}\left(\nabla^{2} \psi-j_{L H}\right)
$$

where $\eta_{\|}(r)$ is the parallel component of the plasma resistivity, $j_{L H}(r)$ is the LHCD current density profile, and $r$ is the radial coordinate in a cylindrical coordinate system. The total current density, $\mathrm{j}(\mathrm{r})$, is related to $\psi(\mathrm{r})$ by

$$
j(r)=\nabla \times \mathbf{B}=\nabla^{2} \psi
$$


Figure 8 shows the calculated evolution of $j(r)$ over the time of the LHCD pulse for the parameters of the discharge shown in figure 1. The $\eta_{\|}$-profile was taken from a TRANSP code calculation of the neoclassical resistivity for this discharge, and the initial $j(r)$ (Ohmic heating only) and $j_{L H}$ profiles were taken from a TSC/LSC code simulation of the discharge. The surface voltage was adjusted to reproduce the experimental $I_{p}$ time evolution. The initial $j(r)$ profile is slightly hollow due to the slow current penetration during the $I_{p}$ ramp-up. It is clear that sufficient drive to produce a negative core current density is present. The skin time and L/R time are both several seconds, so the $j(r)$ profile continues to evolve slowly through the LHCD pulse.

\section{MHD Modeling}

As the core current density decreases through zero to become negative, the poloidal flux function $\psi(\Phi)$ approaches an extremum where the rotational transform $\mathfrak{z} \equiv \partial \psi / \partial \Phi=1 / q$ goes to zero on an interior flux surface. A calculation of equilibrium force balance to second order in inverse aspect ratio shows that existence of a surface with $t=0$ precludes the existence of an equilibrium in toroidal geometry [17]. (The question of whether or not this is more generally true requires more theoretical study.) Instead, the discharge is expected to undergo an $n=0$ reconnection event when $\mathfrak{z}$ goes to zero on an interior flux surface.

The M3D code [12] was used to study $n=0$ reconnection events in discharges with extremely reversed shear. M3D can be used at a number of different physics levels; for this problem, it was used as a nonlinear resistive MHD code in toroidal geometry. The plasma is approximated as a collisional conducting fluid with a scalar pressure and zero perpendicular heat flux. This approximation is valid for the study of global MHD phenomena dominated by cross-field motion because the small gyroradius relative to the plasma radius leads to collisional fluid-like behavior perpendicular to the field lines. The resistive MHD equations are used, along with an additional wave equation which represents fast thermal equilibration along the field lines. (Details of this model are given in reference 12.)

To save computational time and to focus on the $n=0$ reconnection process, the M3D runs were done in two spatial dimensions with an 80 point radial mesh. The time step size is $(0.025) \tau_{A}$ where $\tau_{A}$ is the Alfvén time. $\left(\tau_{A}\right.$ is $\sim 1 \mu$ s for these JET discharges.) The Lundquist number, $\mathrm{S}$, was taken to be $10^{4}$ to keep the computational time practical and to ensure that the fluid approximation is valid. (Actual experimental values are $S=10^{8}$ or 
greater.) The viscosity, $\mu$, was taken to be $10^{-4}$ in normalized units. The initial equilibrium and $\mathrm{j}_{\mathrm{LH}}$-profile were taken from the TSC/LSC simulation at time $\mathrm{t}=1.0 \mathrm{~s}$.

The results of such a simulation are seen in figures 9 and 10 , which show $\psi(R, Z)$ and $\Delta^{*} \psi=\operatorname{Rj}(\mathrm{R})$ at six times. The times are in units of the Alfvén time and are chosen to show the major features of the time evolution. (In figure 9, a small contour interval is used for all but the first time to show the details of the magnetic island evolution; the outer flux surfaces are not shown to avoid saturating the plots.)

The major features of the $\operatorname{Rj}(\mathrm{R})$ and $\psi(\mathrm{R}, \mathrm{Z})$ time evolutions shown in figures 9 and 10 are as follows. The first time shown, $t=12 \tau_{A}$, is shortly after the start of the LHCD pulse. Two off-axis minima in $j(R)$ have developed and $j(R)$ is still positive, although it has already gone negative in two regions above and below the midplane. $B y t=40 \tau_{A}$, $m=2$ islands have appeared above and below the midplane and $j(R)$ has become negative off-axis. Reconnection has started to occur by this time. Reconnection occurs on the inboard side of the plasma axis by $t=172 \tau_{\mathrm{A}}$. By this time, the island surrounding the original magnetic axis has moved to the outboard side and is disappearing. Reconnection then occurs on the outboard side by $t=280 \tau_{A}$. The $j(R)$ spikes at these times are due to the existence of a narrow current sheet in the reconnection regions. The core $j(R)$ then flattens and is close to zero by $t=328 \tau_{A}$. Following this initial cycle, reconnection on the outboard side recurs quasi-periodically, with the next time being approximately $t=412 \tau_{A}$. Thus, the core $j(R)$ is held near zero due to $n=0$ reconnection events, even in the presence of strong off-axis current drive. Because of their $n=0$ nature, these reconnection events are termed axisymmetric sawteeth.

The magnetic field topology predicted by the M3D simulation evolves in a complex way, as seen in figure 9. There are several reasons for this: the non-circular cross section of the JET plasma couples islands with several values of $\mathrm{m}$, the non-inductive and inductive contributions to the total current are comparable, and the plasma $\beta$ is low. Detailed understanding of the evolution of the magnetic topology in this case requires a two-fluid treatment and will be the subject of a future paper. A simpler picture is seen in M3D simulations which were done with either 1) a circular cross section and low $\beta$ as in the above simulation or 2 ) very high $\beta$ and the same plasma cross section as in the above case. (The other parameters of these simulations were similar to those used in the simulation discussed above.)

As an example of the simpler magnetic topology seen in these simulations, figures 11 and 12 show $\psi(R, Z)$ and $\operatorname{Rj}(R)$ at four times from the simulation with a circular cross section. The first time, $t=12 \tau_{A}$, shows the equilibrium just before the $t=0$ surface enters the plasma. An $m=1$ island centered on the inboard midplane has developed by $t=60 \tau_{A}$ 
and $j(R)$ has become negative on the outboard midplane. This is followed by outward motion of the plasma axis and reconnection on the outboard side of the plasma at $t=84 \tau_{A}$. By $t=96 \tau_{A}, j(R)$ is near zero in the core region. The cycle then repeats. This reconnection topology is similar to that of a conventional $q=1$ sawtooth.

It is important to note that the axisymmetric $(n=0)$ sawtooth predicted by the M3D simulations has many similarities to the conventional $n=1$ sawtooth but that there are also some essential differences. Like the $n=1$ sawtooth, it is required that the rational surface $t=n / m$ enter the plasma for the reconnection to occur. This can take place either on-axis for a current density profile with a central extremum, or off-axis when the extremum in the current density profile occurs at a finite radius [13, 18-20]. In the first case, the $\mathfrak{t}=0$ surface appears immediately and reconnection in a small region around the plasma axis should clamp the core current at zero. The second case describes the JET discharge: the core current takes on a finite negative value before the $t=0$ surface appears, as shown in figure 10.

However, the $n=0$ sawtooth is fundamentally different from the $n=1$ sawtooth because it has the same symmetry as the equilibrium state, and it is thus best viewed as a transient loss of equilibrium. As soon as the $\mathfrak{t}=0$ surface enters the plasma, the equilibrium undergoes the $n=0$ reconnection event to obtain its new equilibrium state. This differs from the conventional $n=1$ sawtooth, where an axisymmetric equilibrium still exists when the $t=n / m$ rational surface enters the plasma, but a lower energy equilibrium state becomes accessible once the rational surface has penetrated beyond a certain radius $[21,22]$.

This simulation shows that the $n=0$ MHD activity that arises when the core current becomes sufficiently negative is a reconnection event associated with the transient loss of equilibrium. Clamping of the core current at zero has previously been seen by Huysmans et al, [23], who used reduced MHD simulations in cylindrical geometry to show that a plasma with negative core current is unstable to $n=0$ resistive kink instabilities.

Observation of the axisymmetric sawteeth is difficult because their $n=0$ character implies that their frequency is independent of the toroidal flow speed. The high-q sawteeth shown on the $T_{e}$ traces in figure 1 do not always exhibit precursor and postcursor oscillations, but they are $n=1$ modes when they occur [24]. Thus, the high-q sawteeth are likely to be double-tearing modes, not axisymmetric sawteeth. We plan to perform three-dimensional M3D simulations to study the possible role of $n \neq 0$ reconnection events in redistributing the core current density before the extreme condition $\mathrm{t}=0$ is reached. 


\section{Conclusion}

This paper provides physical insight into JET discharges with nearly zero core current density produced by LHCD injection into the current ramp-up phase. We have shown that accurate equilibrium reconstructions of these discharges are possible using a perturbative technique for solving the Grad-Shafranov equation. Nonlinear resistive MHD simulations in toroidal geometry show that these discharges undergo $n=0$ reconnection events (axisymmetric sawteeth) when the core current density attempts to become negative in the presence of strong off-axis non-inductive co-current drive. The axisymmetric sawteeth redistribute the core current to hold it near zero and therefore provide a possible explanation for why the core current density appears to be clamped at zero in these discharges. A more sophisticated treatment of this phenomenon requires a two-fluid MHD treatment. This is in progress and should allow the frequency of the axisymmetric sawteeth to be predicted. An interesting future experiment would be to attempt to observe the onset of the axisymmetric sawteeth early in the LHCD pulse with the MSE diagnostic.

The existence of a mechanism that holds the core current density at zero in the presence of strong off-axis non-inductive current drive may be important for current density profile control in future long pulse reactors. This is particularly true of spherical torus reactors in which it is desired to eliminate the Ohmic heating windings in the center stack and drive all of the current by off-axis non-inductive current drive and the bootstrap current. A previous study showed that the current would have to be increased very slowly to avoid negative core current density [25] in this scenario. This may not be necessary if reconnection events can be relied upon to prevent negative core current density. 


\section{Acknowledgements}

We would like to thank T. Hender for useful comments on this paper. B. Stratton appreciates guidance from R. Nazikian and the support of K. Young in fostering the JET MSE diagnostic collaboration. This work was conducted under the European Fusion Development Agreement and partly funded by Euratom, the UK Department of Trade and Industry, and the US Department of Energy (contract no. DE-AC02-76-CH03073). 


\section{References}

[1] Levinton, F M et al 1995 Phys. Rev. Lett. 754417

[2] Strait E J et al 1995 Phys. Rev. Lett. 754421

[3] Challis C D et al 2001 Plasma Phys. Control. Fusion 43861

[4] Hawkes N C et al 2001 Phys. Rev. Lett. 87 115001-1

[5] Hawkes N C et al 2001 paper in this issue of PPCF

[6] Hawkes et al 1999 Rev. Sci. Instrum. 70894

[7] Stratton et al 1999 Rev. Sci. Instrum. 70898

[8] Fujita T et al 2001 Phys. Rev. Lett., accepted

[9] Challis CD 2001 paper in this issue of PPCF

[10] Zakharov L E and Pletzer A 1999 Phys. Plasmas 64693

[11] Jardin S C, Bell M G, and Pomphrey N 1993 Nucl. Fusion 33371

[12] Park W et al 1999 Phys. Plasmas 61796

[13] Chang Z et al 1996 Phys. Rev. Lett. 773553

[14] Zarnstorff M C et al 1997 Phys. Plasmas 41097

[15] O'Brien D P et al 1992 Nucl. Fusion 321351

[16] Budny R V et al 1995 Nucl. Fusion 351497

[17] Greene J M et al 1971 Phys. Fluids 14671

[18] Parail V et al 1983 Sov. J. Plasma Phys. 614

[19] Wesson J 1986 Plasma Phys. Control. Fusion 28243

[20] Kleva et al 1987 Phys. Fluids 302119

[21] Bussac M et al Phys. Rev. Lett. 1975351638

[22] Manickam J 1984 Nucl. Fusion 24595.

[23] Huysmans et al 2001 Phys. Rev. Lett., accepted

[24] Hellsten T et al 2001 Proceedings of $28^{\text {th }}$ EPS Conference on Plasma Physics and

Controlled Fusion, Madeira, 2001 (to be published)

[25] Jardin S C 2000 Nucl. Fusion 401101 


\section{Figure Captions}

Figure 1. Time evolution of $I_{p}$, LHCD power, NB power, and $T_{e}$ in a discharge that exhibited a region of nearly zero core current density. MSE diagnostic measurements were made at $3.1 \mathrm{~s}$, or $2.6 \mathrm{~s}$ after plasma initiation.

Figure 2. $T_{e}, T_{i}$, and $n_{e}$ profiles at $3.1 \mathrm{~s}$ in the discharge of figure 1.

Figure 3. Measured polarization angle, $\gamma_{\mathrm{m}}$, minus the zero field offset at $3.1 \mathrm{~s}$ in the discharge shown in figures 1 and 2 . The region around the plasma axis of nearly zero slope implies $B_{Z} \approx 0$ or $j(R) \approx 0$ within measurement errors.

Figure 4. Equilibrium from ESC code reconstruction at $3.1 \mathrm{~s}$ of the discharge shown in figures 1-3. The MSE $\gamma_{m}$-profile was used as a constraint.

Figure 5. Parallel current density profile, $\mathrm{j}_{\|}(\mathrm{x})$, showing near zero core current density with a steep positive gradient to a narrow peak at $\mathrm{x}=0.25$.

Figure 6. Profile of the safety factor, q, corresponding to the current density profile of figure 5 .

Figure 7. $\tan \gamma_{\mathrm{m}}$ from MSE diagnostic measurement and fit from equilibrium reconstruction.

Figure 8. Time evolution of $j(r)$ over the duration of the LHCD pulse predicted by a simple current diffusion model in cylindrical geometry, demonstrating that sufficient offaxis current drive is present to produce a negative core $j(r)$.

Figure 9. Poloidal flux map, $\psi(R, Z)$, at six different times from M3D simulation. The time is in units of the Alfvén time, $\tau_{A}$.

Figure 10. $\mathrm{Rj}(\mathrm{R})$ from M3D code simulation shown in figure 9.

Figure 11. Poloidal flux map, $\psi(R, Z)$, at four different times from M3D simulation with circular plasma cross section. 
Figure 12. $R j(R)$ from M3D code simulation with circular plasma cross section shown in figure 11 . 


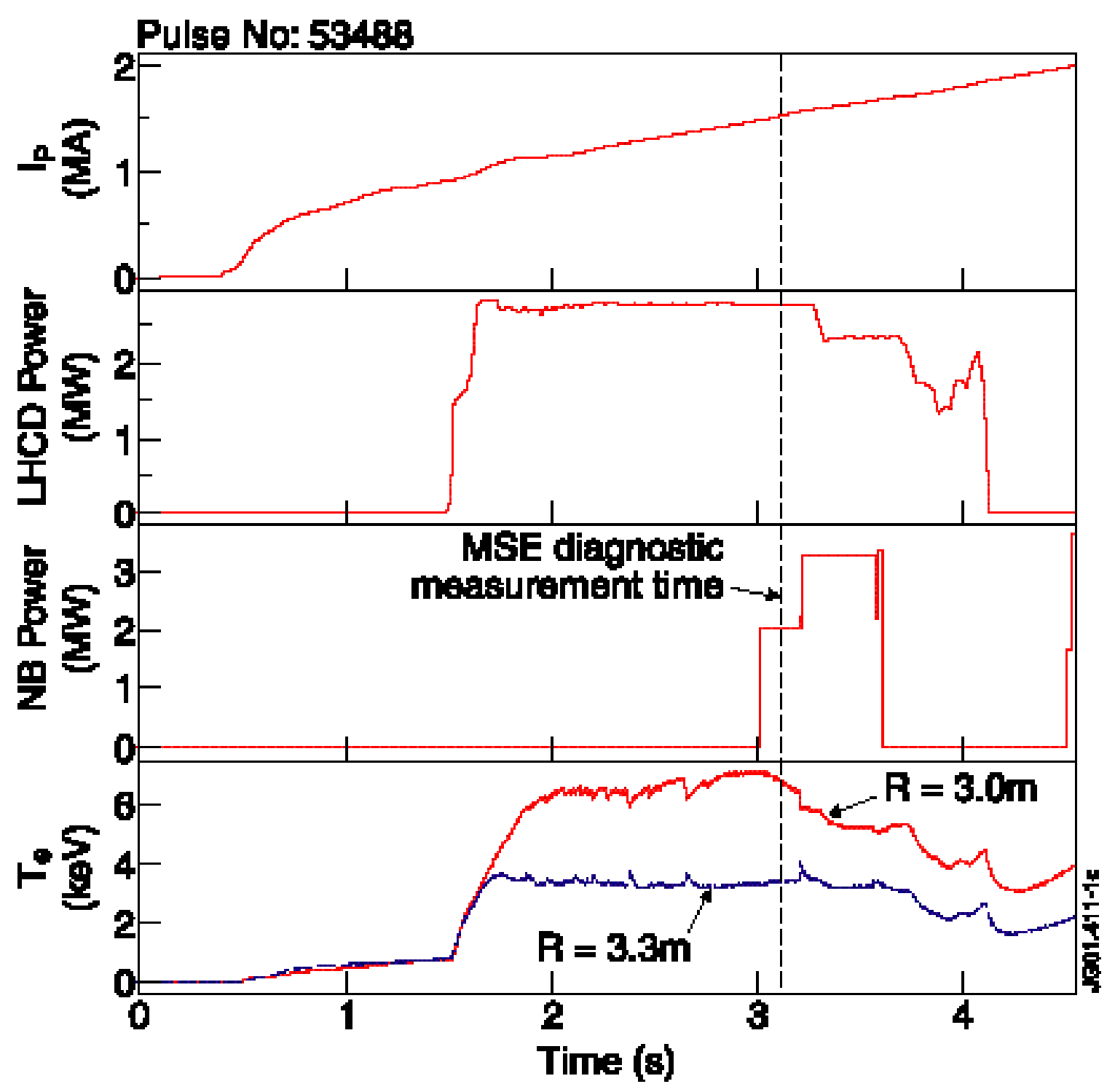

Figure 1 


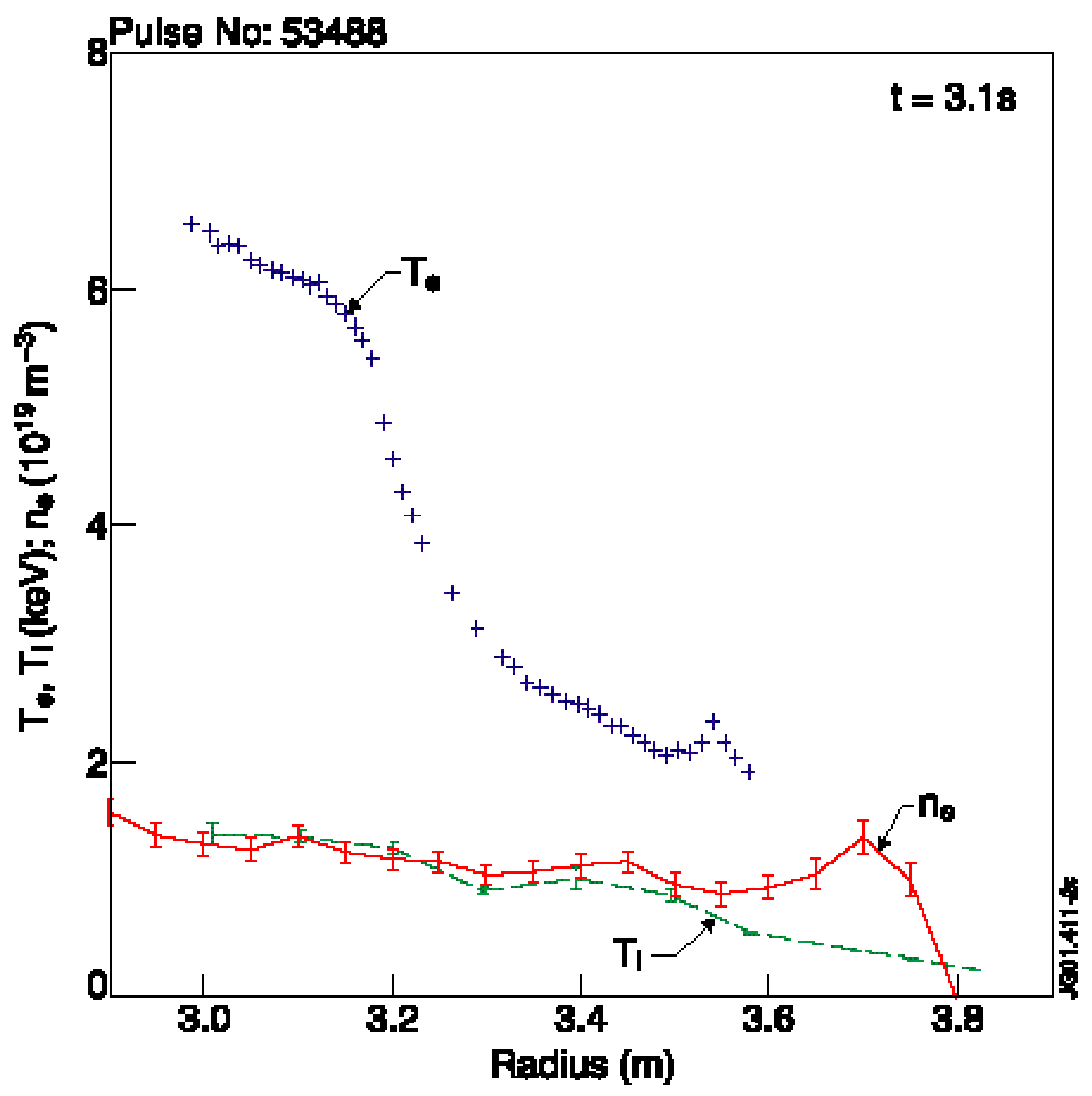

Figure 2 


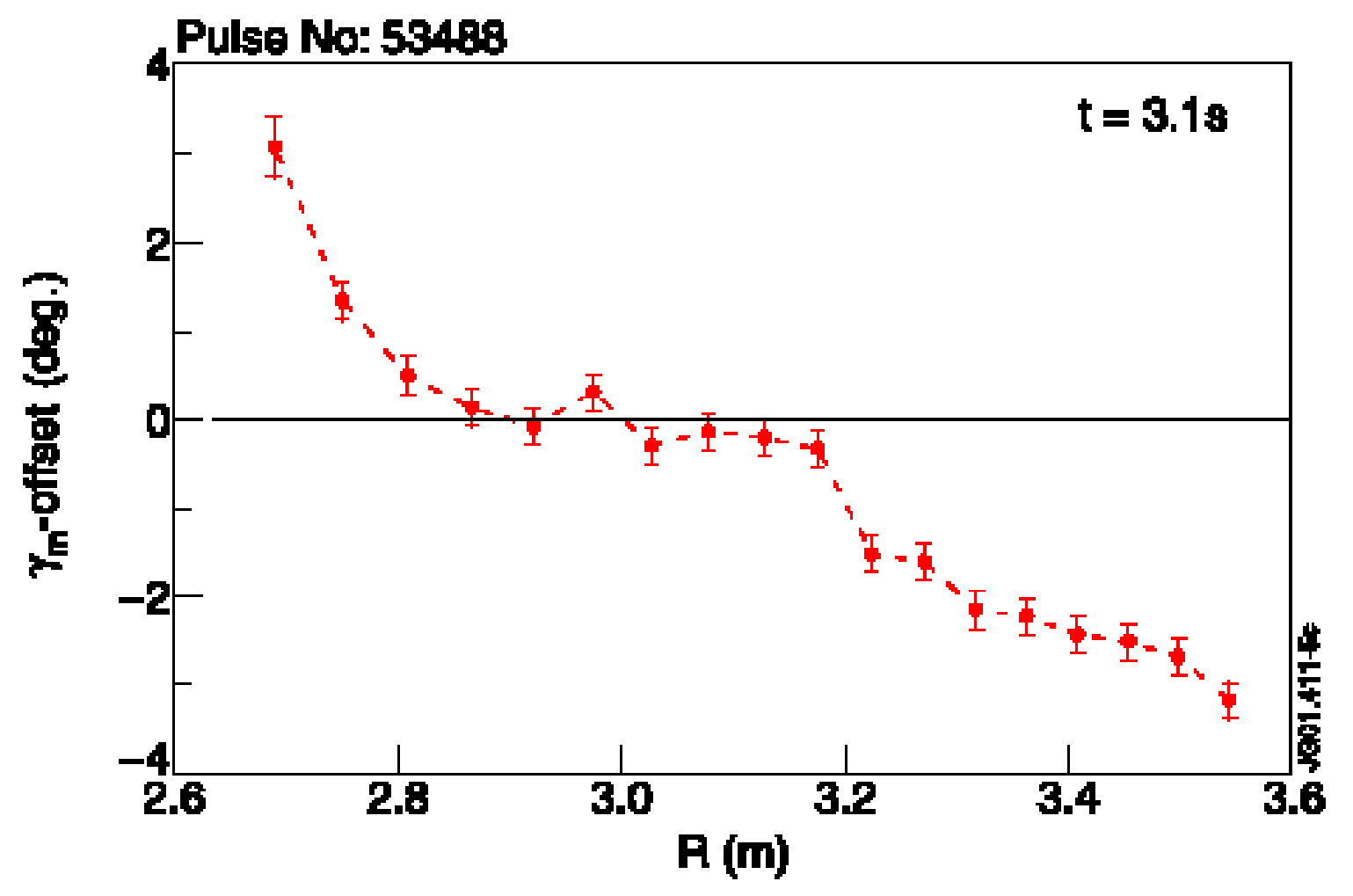

Figure 3 


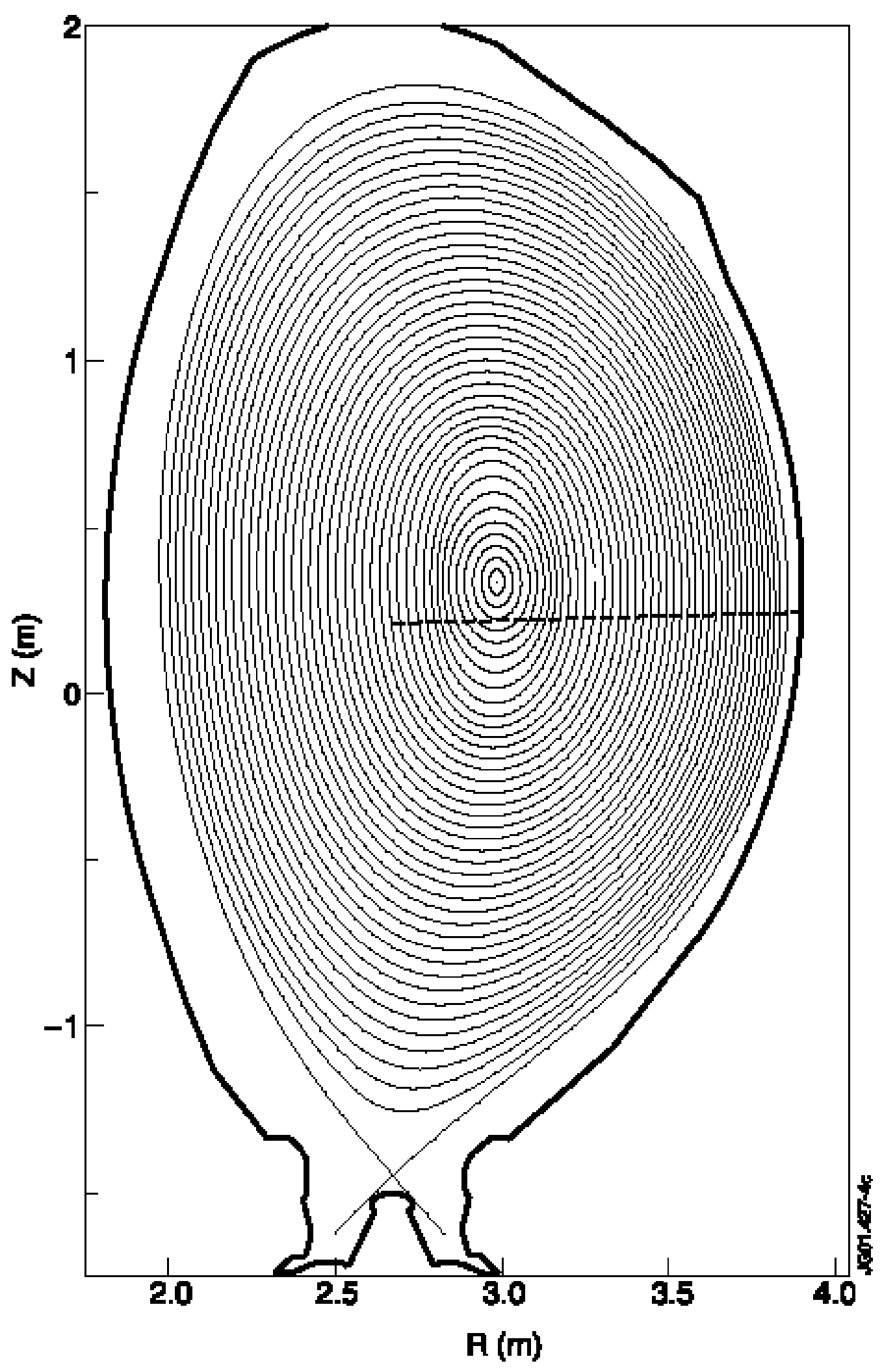

Figure 4 


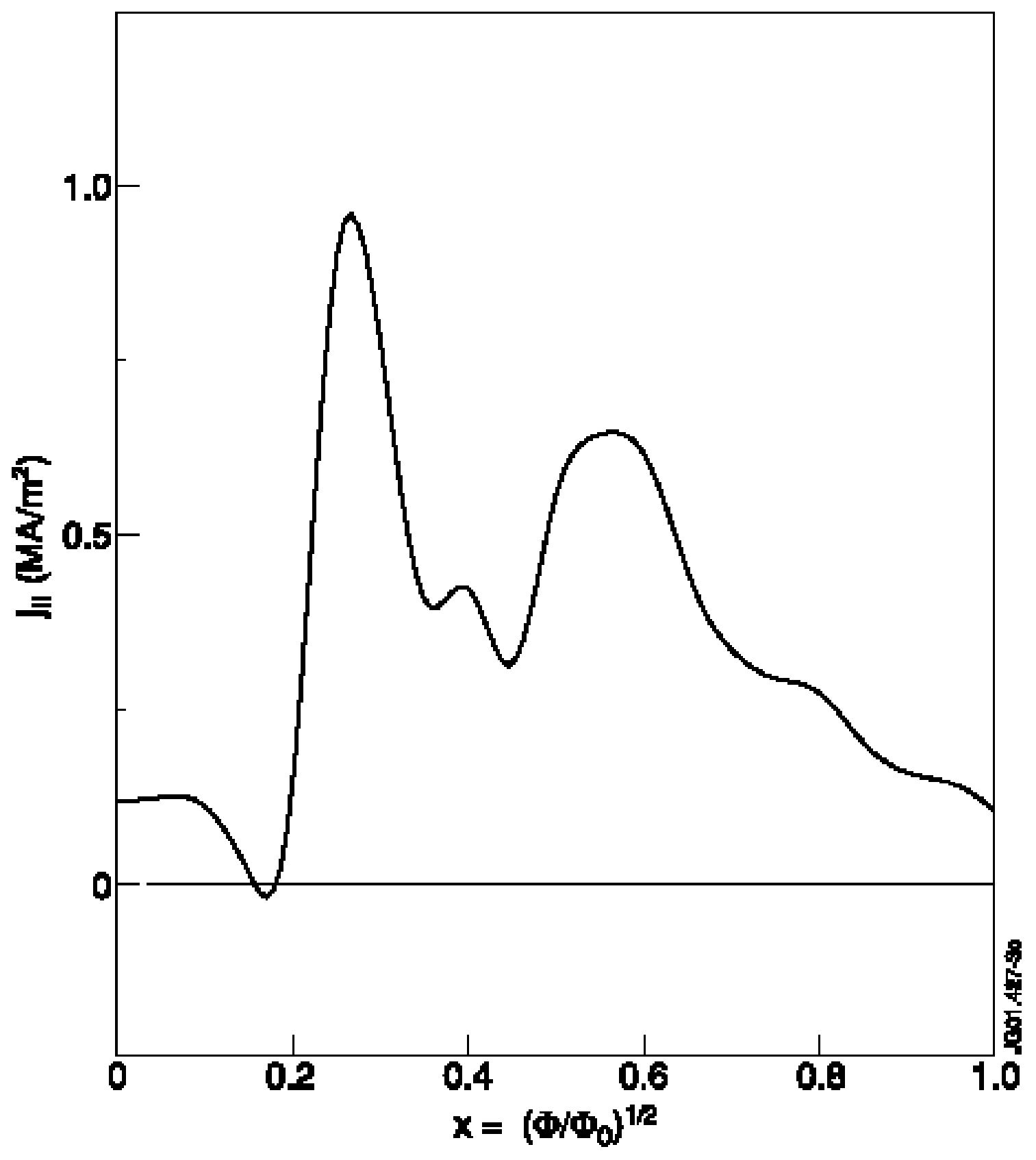

Figure 5 


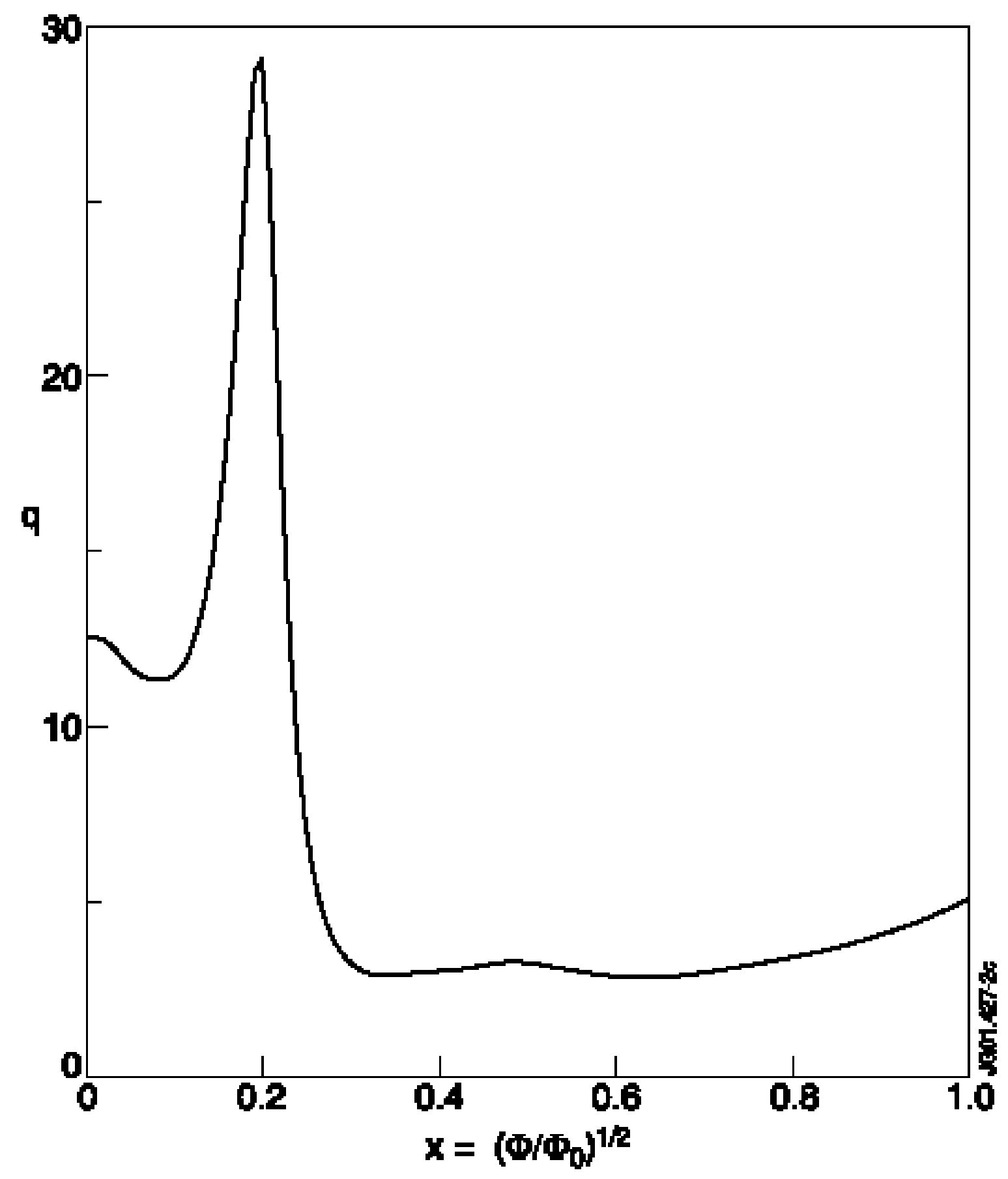

Figure 6 


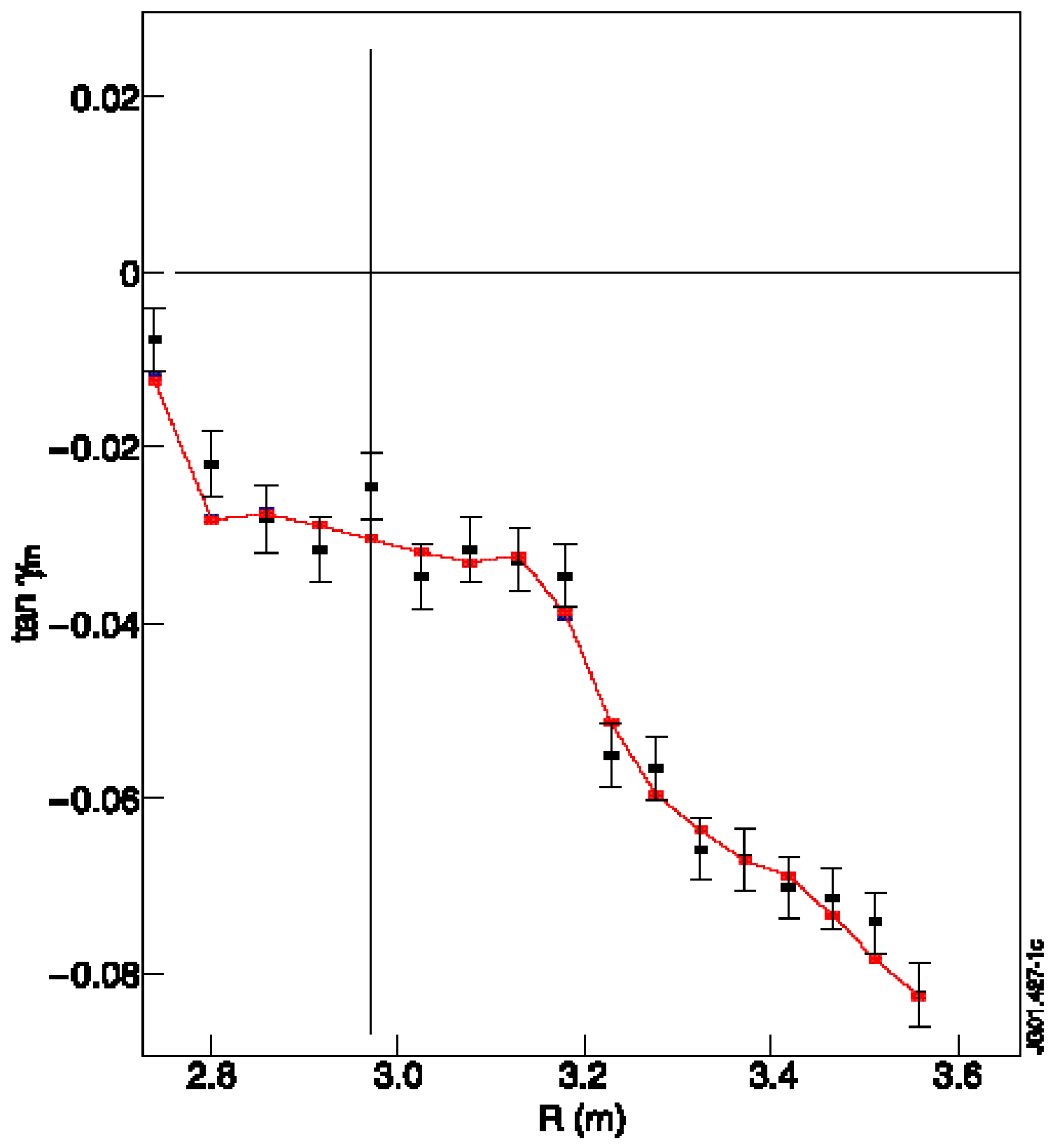

Figure 7 


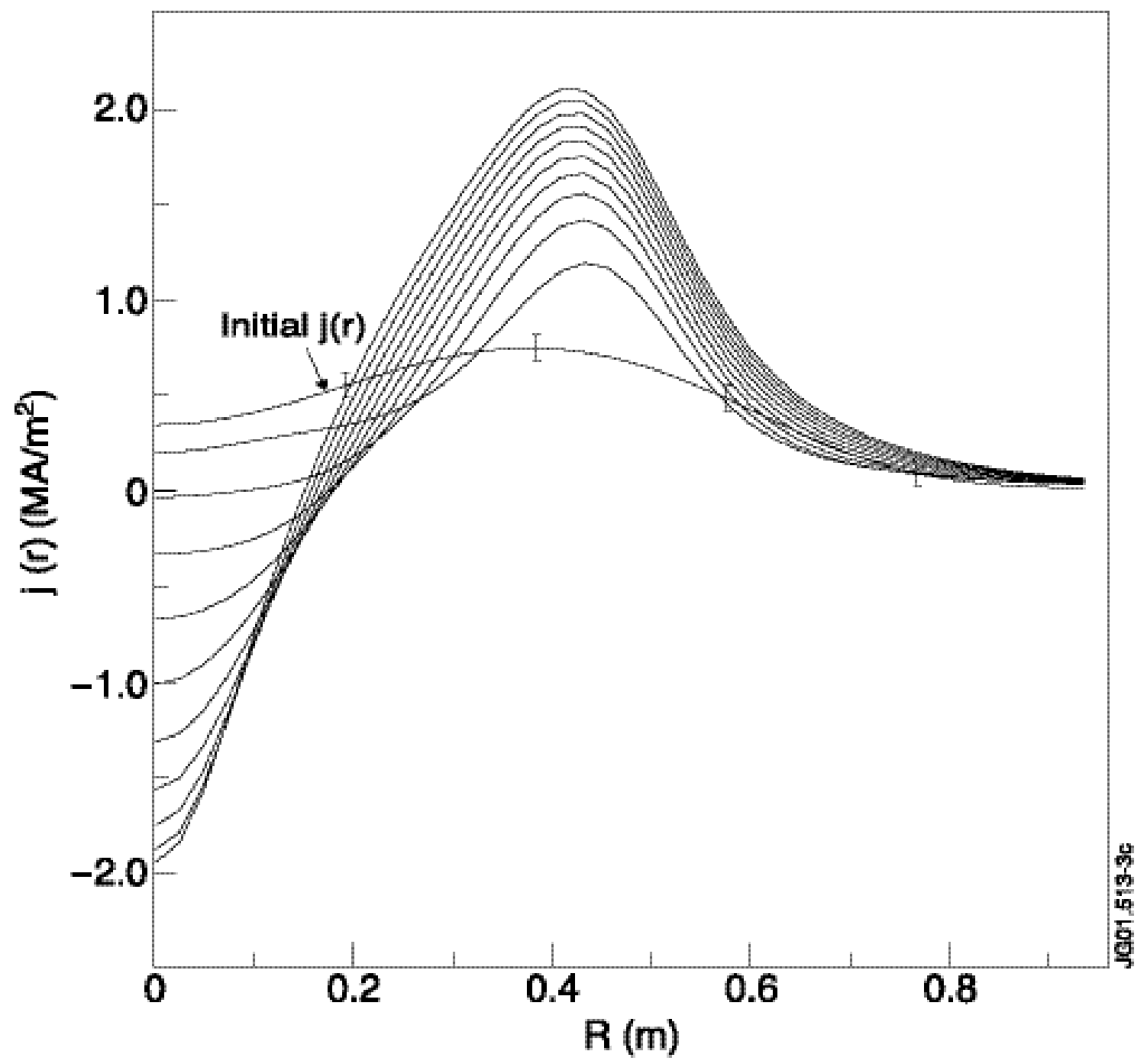

Figure 8 

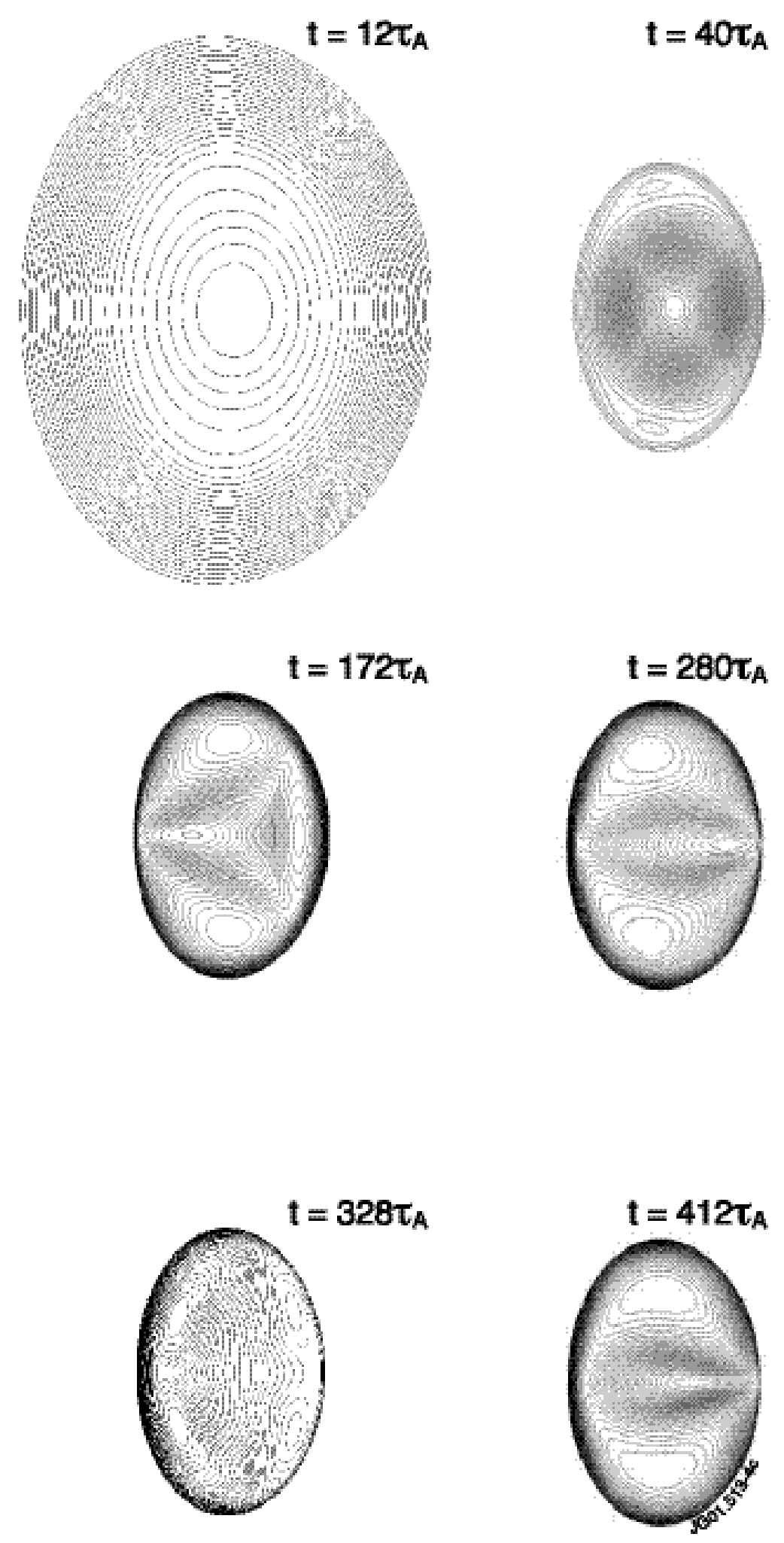

Figure 9 

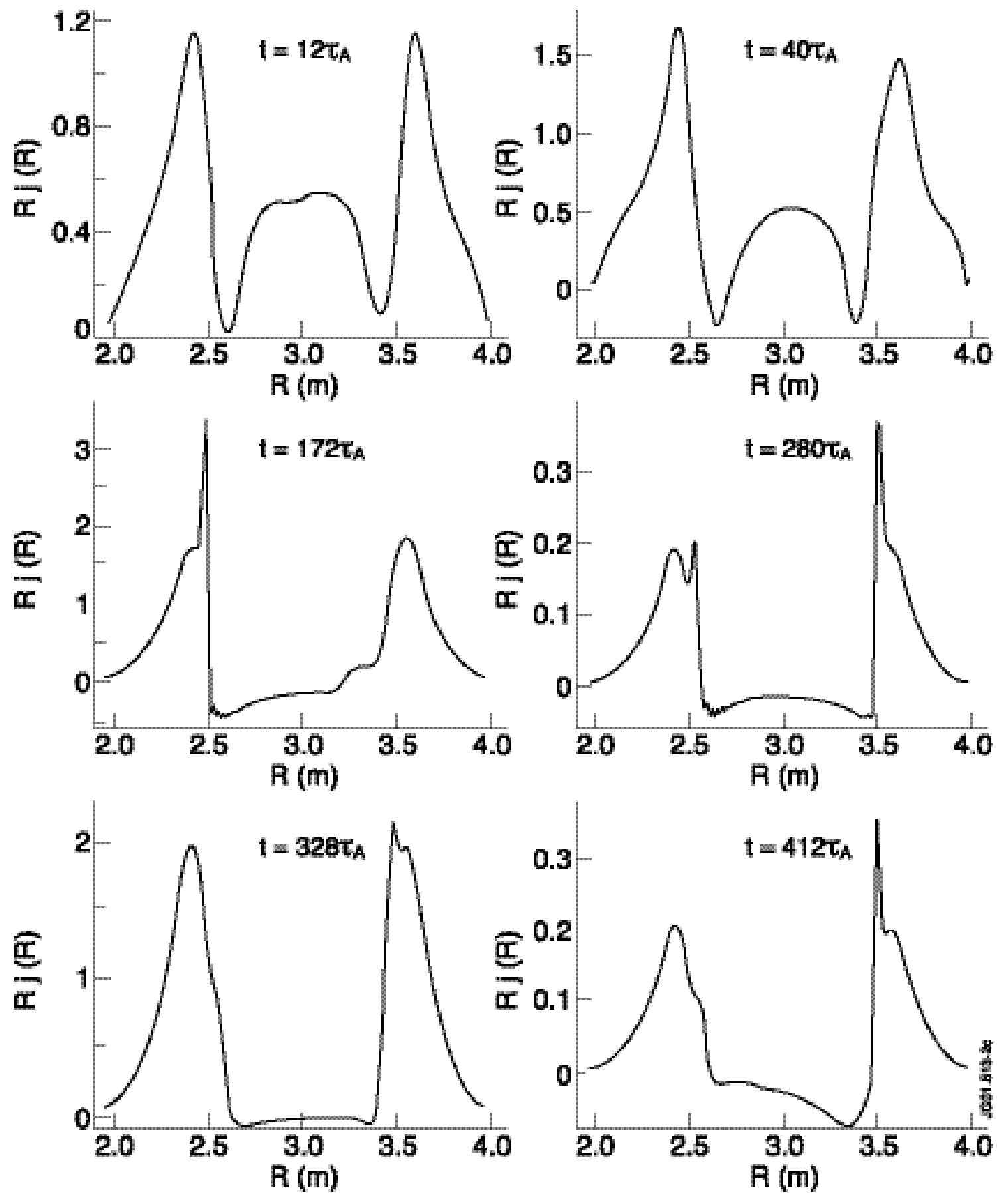

Figure 10 

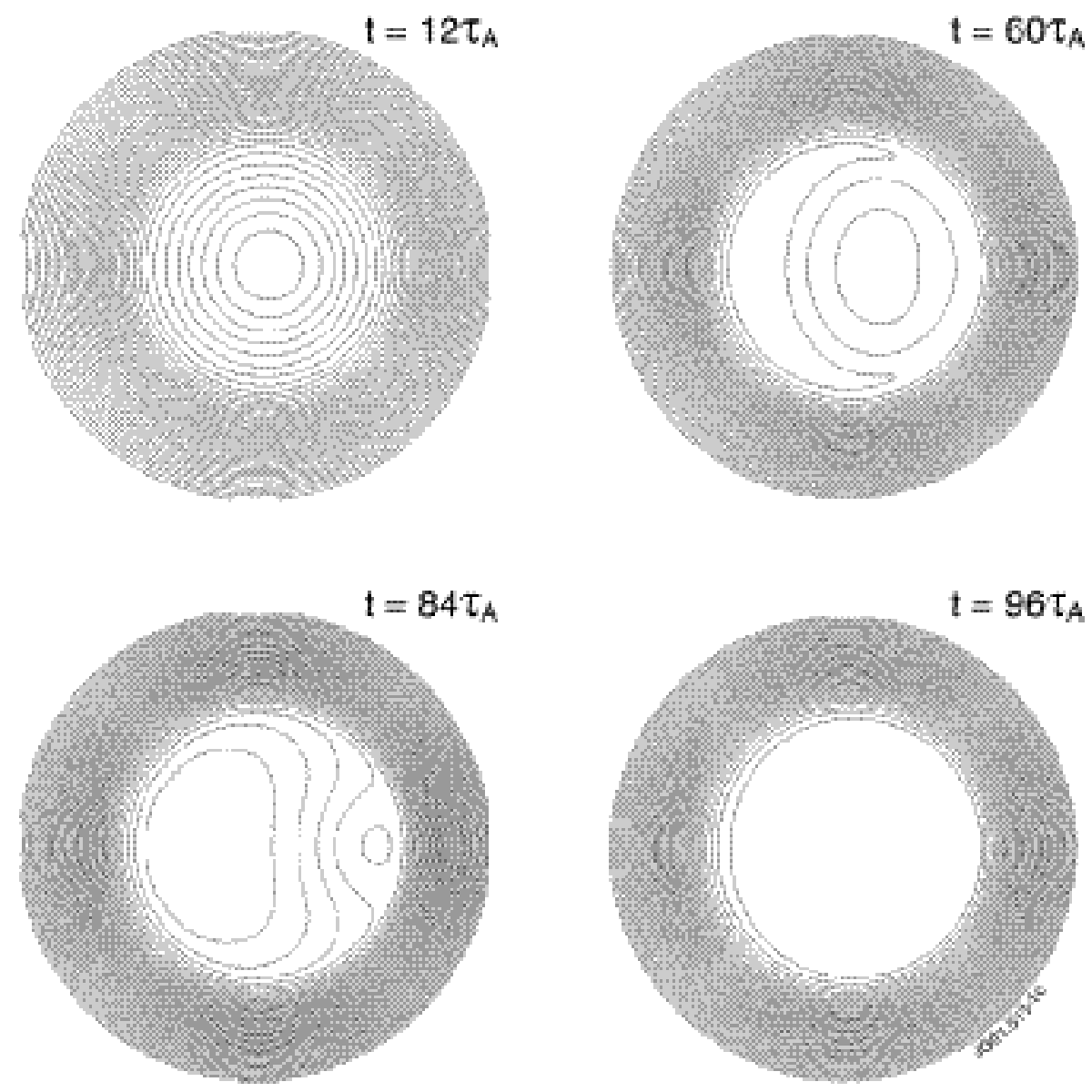

Figure 11 

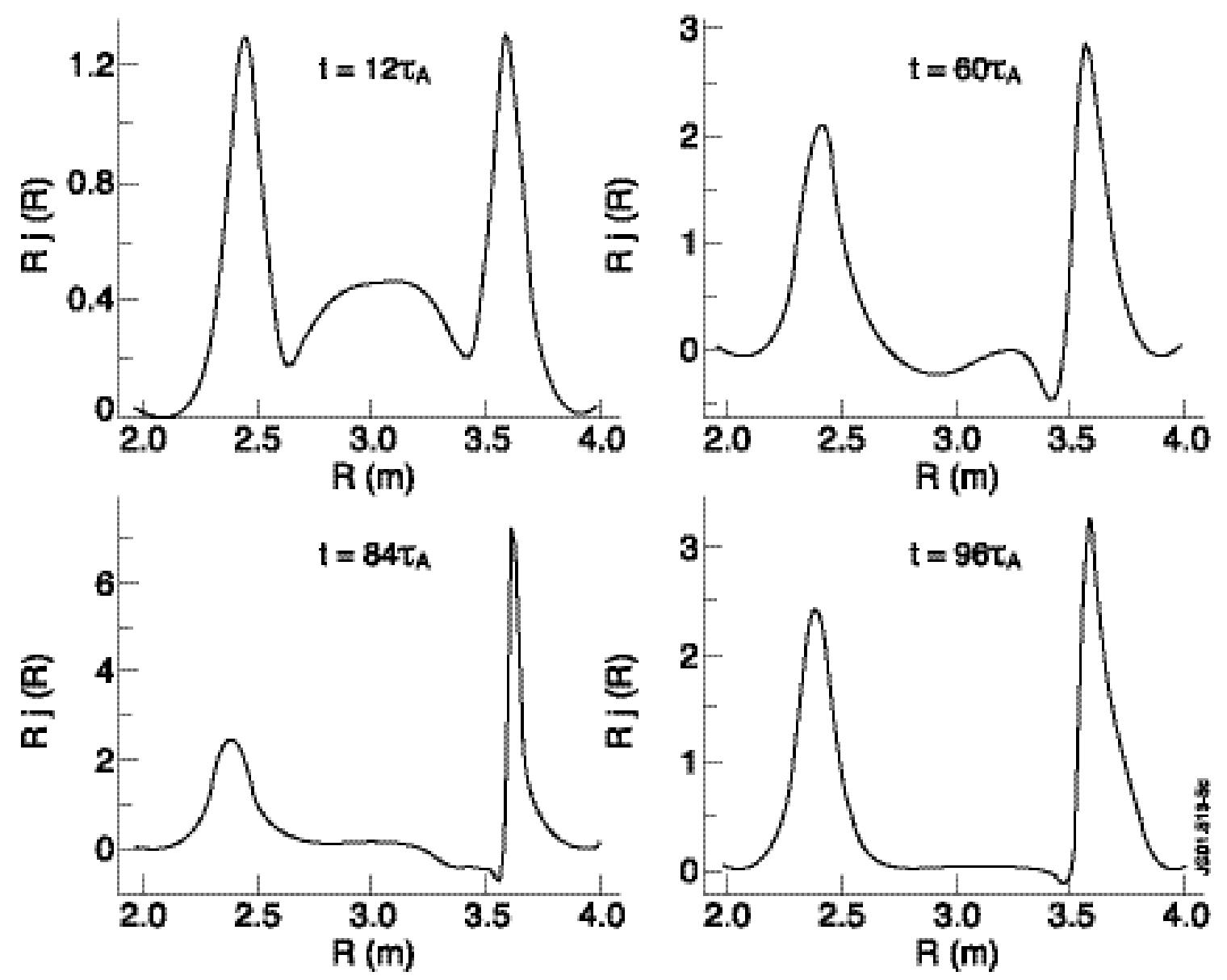

Figure 12 


\section{External Distribution}

Plasma Research Laboratory, Australian National University, Australia

Professor I.R. J ones, Flinders University, Australia

Professor J oão Canalle, Instituto de Fisica DEQ/IF - UERJ , Brazil

Mr. Gerson O. Ludwig, Instituto Nacional de Pesquisas, Brazil

Dr. P.H. Sakanaka, Instituto Fisica, Brazil

The Librarian, Culham Laboratory, England

Library, R61, Rutherford Appleton Laboratory, England

Mrs. S.A. Hutchinson, JET Library, England

Professor M.N. Bussac, Ecole Polytechnique, France

Librarian, Max-Planck-Institut für Plasmaphysik, Germany

J olan Moldvai, Reports Library, MTA KFKI-ATKI, Hungary

Dr. P. Kaw, Institute for Plasma Research, India

Ms. P.J . Pathak, Librarian, Insitute for Plasma Research, India

Ms. Clelia De Palo, Associazione EURATOM-ENEA, I taly

Dr. G. Grosso, Instituto di Fisica del Plasma, Italy

Librarian, Naka Fusion Research Establishment, J AERI, J apan

Library, Plasma Physics Laboratory, Kyoto University, J apan

Research Information Center, National Institute for Fusion Science, J apan

Dr. O. Mitarai, Kyushu Tokai University, J apan

Library, Academia Sinica, Institute of Plasma Physics, People's Republic of China

Shih-Tung Tsai, Institute of Physics, Chinese Academy of Sciences, People's Republic of China

Dr. S. Mirnov, TRINITI, Troitsk, Russian Federation, Russia

Dr. V.S. Strelkov, Kurchatov Institute, Russian Federation, Russia

Professor Peter Lukac, Katedra Fyziky Plazmy MFF UK, Mlynska dolina F-2, Komenskeho Univerzita, SK-842 15 Bratislava, Slovakia

Dr. G.S. Lee, Korea Basic Science Institute, South Korea

Mr. Dennis Bruggink, Fusion Library, University of Wisconsin, USA

Institute for Plasma Research, University of Maryland, USA

Librarian, Fusion Energy Division, Oak Ridge National Laboratory, USA

Librarian, Institute of Fusion Studies, University of Texas, USA

Librarian, Magnetic Fusion Program, Lawrence Livermore National Laboratory, USA

Library, General Atomics, USA

Plasma Physics Group, Fusion Energy Research Program, University of California at San Diego, USA

Plasma Physics Library, Columbia University, USA

Alkesh Punjabi, Center for Fusion Research and Training, Hampton University, USA

Dr. W.M. Stacey, Fusion Research Center, Georgia Institute of Technology, USA

Dr. J ohn Willis, U.S. Department of Energy, Office of Fusion Energy Sciences, USA

Mr. Paul H. Wright, Indianapolis, Indiana, USA 
The Princeton Plasma Physics Laboratory is operated by Princeton University under contract with the U.S. Department of Energy.

\author{
Information Services \\ Princeton Plasma Physics Laboratory \\ P.O. Box 451 \\ Princeton, NJ 08543
}

Phone: 609-243-2750

Fax: 609-243-2751

e-mail: pppl_info@pppl.gov

Internet Address: http://www.pppl.gov 